\title{
Migration of zeolite-encapsulated Pt and Au under reducing atmospheres
}

\begin{abstract}
The encapsulation of noble metals into zeolites is a promising route to generate controlled size distributions of stable metal catalysts. Pinning of single metal atoms to particular binding sites represents the optimal atom-efficiency and is a desirous outcome, despite the propensity of metal clusters to sinter. Currently, sintering resistance of noble metals in siliceous frameworks is incompletely understood, while the role of influencing factors such as adsorbates and exchange of metal type, have not been ascertained. Here, we investigate the binding and migration pathways of atomic Pt and Au in the siliceous zeolite LTA, via density functional global structure optimisation and kinetic Monte Carlo simulations. We show that strong binding of Pt atoms to the siliceous framework severely hinders migration, while $\mathrm{Au}$ diffuses freely through the pore. Reducing agents $\mathrm{CO}$ and $\mathrm{H}_{2}$ change the preferred binding site of Pt, induce volatility, reduce migration barriers and thereby promote particle growth. This work provides an atomistic picture of single atom kinetics inside high-silica zeolites, which represent a fundamental basis for understanding nano-catalyst deactivation.
\end{abstract}

\section{Introduction}

Small nanoparticles and clusters of noble metals, in particular Pd, Pt and Au have prompted much interest in the last 20 years as highly active and selective catalysts for a wide range of industrially important reactions. ${ }^{1-5}$ These applications range from redox reactions for exhaust emissions abatement, ${ }^{6-7}$ to hydrocarbon upgrading for biofuels, ${ }^{8-9}$ to fine chemical transformations in the pharmaceutical industry ${ }^{10-11}$. In all cases, however, the great expense and low stability of noble metal catalysts is a problem to be solved. High cohesive energies lead to deactivation via agglomeration in the liquid phase and migration and sintering in the case of surface-supported heterogeneous catalysis. ${ }^{12-13} \mathrm{~A}$ promising solution to both issues is encapsulation of the active species into inert frameworks such as zeolites or MOFs, ${ }^{14-22}$ which 
hinder sintering by two mechanisms: physical restriction to growth by confinement in the zeolite pore, and pinning of single atoms and clusters to particular binding sites in the framework. ${ }^{23-25}$

In the case of physical confinement, there are several recent synthetic methods which produce trapped particles of $\mathrm{Pt}$ or $\mathrm{Pd}$ inside zeolite pores, either by co-precipitation of precursors of both metal and zeolite, or by mechanical trapping via the 2D 3D condensation of the framework, as was recently demonstrated for MWW by Corma et al., ${ }^{26-27}$ and IPC-2 and IPC-4 by Cejka et al. ${ }^{28-29}$ It is difficult to precisely maintain the size distribution and thermal stability of the produced clusters via chemical means. However, these methods have shown excellent promise in catalytic tests towards reactions such as nitroarene hydrogenation and dehydrogenation of propane to propylene..$^{30-31}$

In the case of atom trapping, which represents the maximum efficiency of SAC, ion exchange in isomorphously substituted frameworks is a common source of highly-dispersed noble metal atoms. ${ }^{32}$ Exchange of alkali metal cations by $\mathrm{Cu}, \mathrm{Pd}, \mathrm{Pt}$ at aluminium sites leads to oxidised single atom sites and small metal-oxo clusters, which are used in several industrial applications. This method suffers from low concentrations of active species, and a lack of atomistic understand of the nature of the catalyst.

Several publications have highlighted the unusually high stability of single atoms and small clusters of Pt in dehydrated, high-silica zeolites. ${ }^{26}$ These works raised the question of the nature of the atom-trapping ability of zeolites, in particular small pore frameworks such as chabazite (CHA). By understanding the conditions, choice of framework and metal by which such trapping is maximised, the rational design of encapsulated SAC may ultimately be reached. We recently showed that in high silica Linde Type A (LTA), Pt atoms are bound tightly to Al sites via an insertion mechanism into the Brønsted acid AlO-H bond. More strikingly, we observed that even in cages where no $\mathrm{Al}$ is present, $\mathrm{Pt}$ atoms can be strongly bound to the framework, via a spontaneous, cage-breaking insertion mechanism at the 6-ring. ${ }^{33}$ Hence it is 
not only the presence of $\mathrm{Al}$ that promotes sintering resistance, the local coordination environment of the zeolite framework also plays a major role and is a general effect that applies to other topologies, including CHA, FAU and SOD.

An additional complication to understanding the behaviour of zeolite-encapsulated single metal atoms is the role of adsorbates. The application of encapsulated metal atoms/clusters in heterogeneous catalysis requires the adsorption of small molecule adsorbates from the gas phase. These adsorbates are non-inert with respect to oxidation/reduction of the metal, and to the kinetics and dynamics of cluster migration, growth and redispersion. ${ }^{34}$ In the case of $\mathrm{CO}$, it is unclear whether the adsorbate promotes or hinders particle growth. While CO may destabilise the metal-support complex, enhancing metal lability in the form of $M(C O)_{n}$, and therefore accelerate the thermodynamically favourable sintering process, it has also been reported to lead to trapping of the metal atom at Al sites in zeolites, for example in the form of $\mathrm{M}(\mathrm{CO})_{2}(\mathrm{M}=\mathrm{Rh})$. Furthermore, $\mathrm{CO}$ has been proposed to be responsible for fragmentation of M-M bonds, both experimentally, and computationally for Pt clusters. Hence, the precise role of $\mathrm{CO}$ in the dynamics of labile metal sites in zeolites is not resolved.

In this work, we extend our analysis of the Pt-zeolite interaction in high-silica zeolites, to examine the effects of common reducing adsorbates $\mathrm{CO}$ and $\mathrm{H}_{2}$ on the stability, migration routes and dissociation energetics for $\mathrm{Pt}$, and estimate the kinetics of migration via a microkinetic model. Furthermore, the effect of exchanging the metal with another catalytically relevant noble metal, Au is investigated.

\section{Models and Methods}

\subsection{Model}

The zeolite model is the purely siliceous LTA, which contains $24 \mathrm{~T}$ sites. The structure of LTA is made up of sodalite cages (volume $718.4 \AA^{3}$ ), denoted $\beta$-cage, which are connected to the larger $\alpha$-cages (volume $974.8 \AA^{3}$ ) via 6-rings of diameter $2.8 \AA$. Alpha cages are connected 
together via 8-rings of diameter $4.3 \AA$, forming a porous system that is connected in 3 dimensions. In a previous publication, ${ }^{33}$ we developed a naming system for single atom binding sites in LTA, based on previous conventions. In this system ring sites are labelled S1, S2 and S3, for the 6-ring, 8-ring and 4-ring, respectively. ${ }^{35}$ Intermediate sites in which Pt binds to the framework oxygen which connects two rings are labelled S1/S2, S1/S3 and S2/S3. Where necessary, an $\alpha$ or $\beta$ is included in superscript to denote the cage in which the site is located. A further notation to denote a broken framework site is the asterisk *. For Pt@LTA, this occurs only for the $\mathrm{S} 1^{*}$.

\subsection{Computational Method}

\subsubsection{Global structure optimisation}

The optimal structures of LTA-encapsulated metal atoms were located via a global optimisation approach. A basin-hopping algorithm ${ }^{36-37}$ was employed at the PBE-D3 ${ }^{38-39}$ level of theory with loose convergence criteria for 500 steps within the ASE package. ${ }^{40}$ The wavefunction cutoff, energy difference and force criteria were $450 \mathrm{eV}, 10^{-4} \mathrm{eV}$ and $2 \times 10^{-2}$ $\mathrm{eV} / \mathrm{A}$, respectively. A Cartesian moveclass of metal cluster translations with a maximum stepwidth of $1.2 \AA$, and a Metropolis temperature of $200 \mathrm{~K}$ ensured a good balance to efficiently explore configuration space. Subsequent reminimisation of all low-energy minima, was then performed with tighter convergence criteria, allowing full relaxation of all atoms. The plane-wave wave function cutoff was chosen to be $700 \mathrm{eV}$, with energy and force criteria of $10^{-5} \mathrm{eV}$ and $10^{-2} \mathrm{eV} / \AA$, respectively. For CO-covered vacuum clusters, the structures are located via a recursive global optimization scheme. First, 2500 candidate initial structures of the appropriate composition were randomly generated, with Pt atoms inside a sphere of $5 \AA$, and CO molecules randomly arranged in the shell from 5-5.5 $\AA$, using the Molclus code. ${ }^{41}$ Local minimisation of candidate structures was performed within a tight binding approximation, using the XTB code of Grimme. ${ }^{42}$ Promising candidates were then tightly reoptimized with 
VASP. For CO-covered clusters in the zeolite, $\mathrm{CO}$ molecules were added to the putative global minimum structure for the bare Pt 5 @LTA obtained in our previous work. ${ }^{33}$

Gaussian smearing of electronic states was applied, with a smearing width of $0.1 \mathrm{eV}$. K point sampling was restricted to the gamma point. Spin unrestricted calculations were employed for both zeolite-bound and gas phase metal clusters. Charge analysis was performed using the Bader charge partitioning scheme. ${ }^{43-46}$ Migration barriers were calculated by locating transition state between local minimum, via the climbing image nudged elastic band and dimer method in the TST package of VASP. ${ }^{47-49}$

The incorporation energy for species $X$ at a site in the zeolite is defined as the energy required to bring $X$ to a particular site in the zeolite from the vacuum at infinite distance, for example:

$$
E_{\text {ind }}(P t C O)=E(P t C O @ L T A)-E(L T A)-E(P t C O(g))
$$

where $E$ is the total electronic energy, as approximated by the density functional. The adsorption energy is a measure of the average energy required to connect $\mathrm{n}$ adsorbates to a $\mathrm{Pt}_{\mathrm{n}}$ cluster with respect to the optimal separated configuration. In the vacuum phase, the reference is the $\mathrm{Pt}_{n}$ cluster in isolation and a $\mathrm{CO} / \mathrm{H}_{2}$ molecule in isolation. In the zeolite, the reference is the cluster in its optimal encapsulated configuration and $\mathrm{CO}$ in the zeolite pore.

$E_{a d s}\left(P t_{n}(C O)_{m} @ L T A\right)=E\left(P t_{n}(C O)_{m} @ L T A\right)-E\left(P t_{n} @ L T A\right)-m * E_{i n c}(C O)$

$E_{a d s}\left(P t_{n} C O_{m}(g)\right)=E\left(P t_{n}(C O)_{m}(g)\right)-E\left(P t_{n}(g)\right)-m^{*} E(C O(g))$

for the given configuration, whether encapsulated into the zeolite or isolated in the vacuum.

\subsubsection{Kinetic Monte Carlo}

To investigate the kinetic properties of encapsulated single metal atoms in the low concentration limit, we developed a kinetic Monte Carlo code. The potential energy surface is reformulated as a graph, in which the nodes are associated with the set of minima $\{i\}$ and are connected by transition states. For exemplary transition $i \rightarrow j$, the transition state has 
energy $E_{i}{ }^{*}=E^{T S}{ }_{i \rightarrow j}-E_{i}$. Note that in this notation, $E_{j}{ }^{*}=E^{T S} S_{j i}=E_{i}{ }^{*}+\left(E_{i}-E_{j}\right)$. The first order rate constants for each transition are calculated via kinetic rate theory, in which the rate $(k)$ is given by:

$k=\frac{k_{B} T}{h} \frac{Z_{i}^{*}}{Z_{i}} e^{\frac{-E_{i}^{*}}{k_{B} T}}$, where $\mathrm{k}_{\mathrm{B}}$ is Boltzmann's constant, $\mathrm{T}$ is the temperature, $\mathrm{h}$ is Plank's constant and $Z_{i}^{*} / Z_{i}$ is the quotient of the partition functions for the transition state and initial state of the step. As the reaction network contains no (non-frustrated) translations, rotations or desorption steps, the partition functions are modelled by the vibrational partition function:

$$
Z_{i}=\Pi_{a} \frac{1}{1-e^{\frac{-E_{a}}{k_{B} T}}}
$$

Where a runs over all vibrational normal modes. Tests showed that the results were insignificantly affected by the approximation $\mathrm{Zi}^{*} / \mathrm{Zi}=1$, and so the Arrenhius prefactor is reduced to $\mathrm{k}_{\mathrm{B}} \mathrm{T} / \mathrm{h}$, which simplifies simulations and avoids the disproportionate errors which are known to result from inaccurately approximated low-frequency modes.

In each step ( $n$ ) of the $k M C$ simulation, the list of possible endpoints $\{j\}$ for a microkinetic step starting from site $\mathrm{i}$ is populated, based on the currently occupied site. $\mathrm{j}$ is selected at random, from a block vector weighted by the individual rate constants for the $i \rightarrow j$ transition, $r_{j}$. The occupied site is then updated, and the time $t$ advanced based on a Poisson distribution, with equation:

$$
t_{n+1}=t_{n}-\frac{\ln (x)}{\sum_{j} r_{j}}
$$

where $\mathrm{x}$ is a random number in the range $[0,1)$. The equilibration time $(\tau)$ for the system is defined as the simulation time required for the distribution of occupation probabilities to reach the distribution predicted by a Boltzmann distribution of the energies of the minima $\left\{E_{i}\right\}$, to within a tolerance of $0.1 \%$. Five simulations from each initial site, of duration $t>\tau$ were then run, from which the average site occupation lifetimes $\left\langle t_{i}\right\rangle$ are calculated for all $i$. Synthesis procedures for Pt@zeolites often involve calcinated steps at temperatures of 540 ${ }^{\circ} \mathrm{C}(813 \mathrm{~K})$, and catalytic experimental temperatures reach temperatures of $400-500{ }^{\circ} \mathrm{C}(673-$ 
$773 \mathrm{~K})$. Hence, we choose a temperature range which extends from room temperature to these extreme temperatures $(300-800 \mathrm{~K})$ for $\mathrm{PtCO}$ and $\mathrm{PtH}_{2}$ and extend this range to $1000 \mathrm{~K}$ for $\mathrm{Pt}$, which is more difficult to equilibrate at low temperatures.

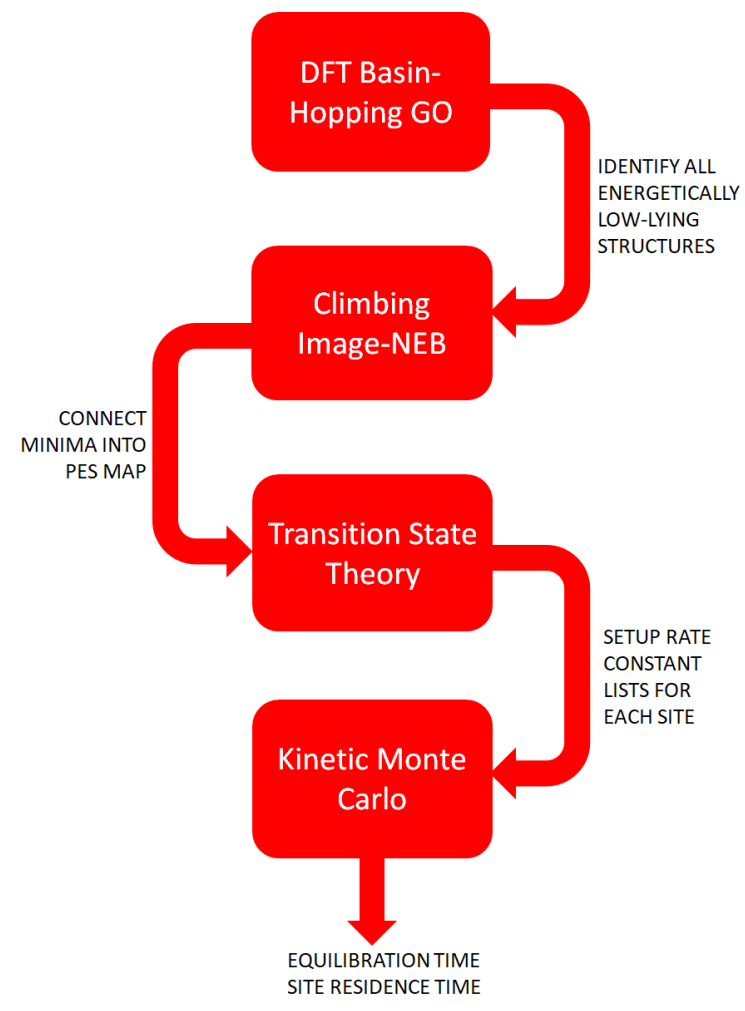

Figure 1: Schematic of the computational process employed in the current work

\section{Results}

\subsection{Encapsulation of Pt in zeolite LTA}

\subsection{1. $P t_{1} @ L T A$}

Pt atoms that are encapsulated into the siliceous LTA zeolite are preferentially located in the centre of the 6-ring, in the plane of the ring, in sites which are denoted S1* (Figure 2). In this site, an $\mathrm{Si}-\mathrm{O}$ bond is broken, giving rise to a defective framework, with a near-linear O-Pt-O group in the plane of the broken 6-ring. This structure was confirmed to be stable, via higher quality hybrid and meta-GGA DFT calculations, and at finite temperature via NVT ab initio MD simulations at $1500 \mathrm{~K}$. This global minimum structure has an incorporation energy of $-2.39 \mathrm{eV}$. Migration from the $\mathrm{S}^{*}$ site is hindered by high barriers to adjacent local minima, with the 
exception of the ring-closing step $\mathrm{S} 1^{*} \rightarrow \mathrm{S} 1$, which only leads to further migration via the ring re-opening reverse step, and is therefore a dead-end branch on the energy landscape. Diffusion through the zeolite pore proceeds with a minimum effective barrier of $1.69 \mathrm{eV}$, via a multiple step path which passes through the 8-ring site (denoted $\mathrm{S} 2_{4}$ ): $\mathrm{S} 1^{*} \rightarrow \mathrm{S} 1 / \mathrm{S}_{\alpha} \rightarrow$ $\mathrm{S} 2 / \mathrm{S}_{\alpha} \rightarrow \mathrm{S} 2_{4} \rightarrow \mathrm{S} 2 / \mathrm{S} 3 \alpha \rightarrow \mathrm{S} 1 / \mathrm{S}_{\alpha} \rightarrow \mathrm{S} 1^{*}$.

The exceptional stability of the $\mathrm{S}^{*}{ }^{*}$ is related to the closure of the Pt sd band through hybridisation with oxygen $2 p$ states, via the formation of covalent bonds to the framework. Additional charge is transferred to the Pt atom from the framework by this interaction (around 0.2 electrons). By contrast, in the $\mathrm{S} 1 / \mathrm{S} 3_{\alpha}$ site, which is the adjacent intermediate site along the diffusion pathway and does not exhibit any framework breakage, negligible charge is transfered to Pt (<0.1 electrons). The DOS for $\mathrm{S} 1 / \mathrm{S}_{\alpha}$ (Figure $2 \mathrm{c}$ ) shows an unfilled Pt sd state at $+0.76 \mathrm{eV}$ and does not benefit from the strong stabilising interaction that results from local framework breakage, giving rise to a significantly smaller incorporation energy of -1.22 eV.

a)

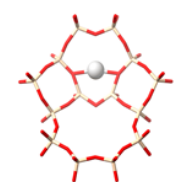

S1 -2.08
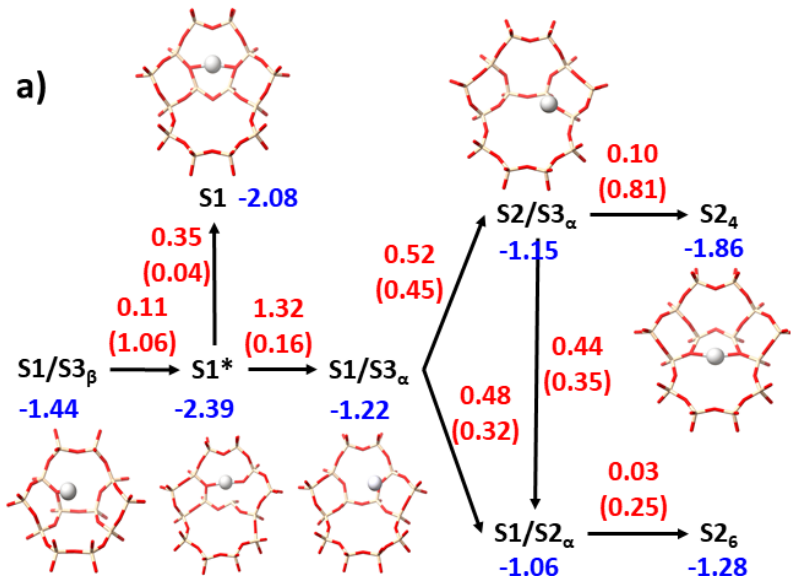

$(0.81)$

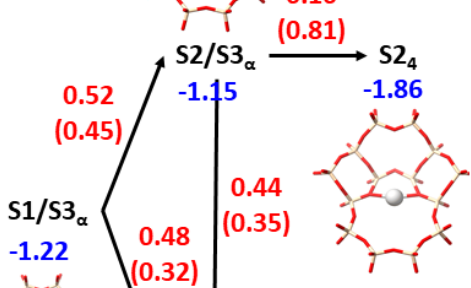

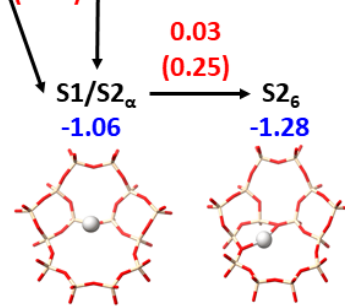
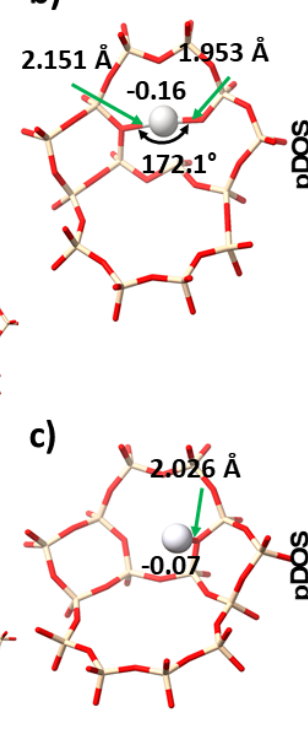

b)
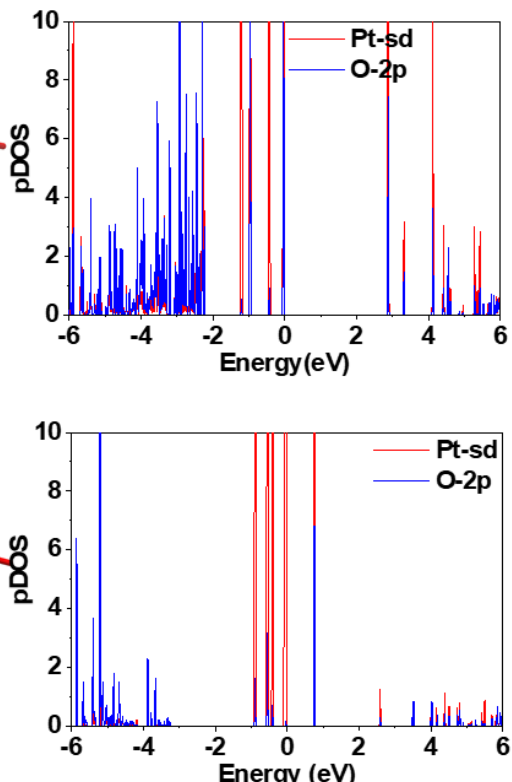

Figure 2:a) Graph representation of the potential energy landscape of Pt@LTA. Incorporation energies in blue (eV), elementary step barriers in red (eV). Reverse barriers are in parentheses. b) Structure and projected density of states (pDOS) for global minimum S1* site. c) Structure and pDOS of the $\mathrm{S} 1 / \mathrm{S} 3_{\alpha}$ site. 
Analysis of the Boltzmann-weighted distribution of occupation probabilities (Table 1) shows that the landscape is dominated by occupation of the S1* site over the synthetically and catalytically relevant temperature range. The probability of $\mathrm{S} 1 *$ occupation only decreases below $90 \%$ at $\mathrm{T}>1510 \mathrm{~K}$, far above the temperatures of catalysis or post-synthetic calcination. Despite the energetic preference for the 6-ring site, the 8-ring sites are deep-lying kinetic traps on the potential energy surface, with high escape barriers. Therefore, it is instructive to estimate the kinetics of the migration process between binding sites.

Each of the local minima on the potential energy landscape are accessible via a series of discrete elementary steps, interconnected via single transition states, as characterised in the energy landscape graph in Figure 2. Kinetic Monte Carlo (kMC) simulations were performed to estimate the equilibration times of the system, and the average occupation lifetimes of each site, at various experimentally relevant temperatures (Table 1). At $300 \mathrm{~K}$ and $500 \mathrm{~K}$, the equilibration time was longer than the available maximum simulation time. At $500 \mathrm{~K}$, the lower bound for equilibration time is $0.2 \mathrm{~s}$, corresponding to approximately $10^{9} \mathrm{kMC}$ steps. At $800 \mathrm{~K}$, the equilibration time is $1.3 \mathrm{~ms}$, and at $1000 \mathrm{~K}$ is $0.1 \mathrm{~ms}$. At elevated temperatures, 800 $\mathrm{K}$ and $1000 \mathrm{~K}$, the $\mathrm{S} 1 *$ site is in rapid equilibrium with the dead-end S1 site, with occupation lifetimes on the ns timescale. The 8-ring site, $\mathrm{S}_{4}$ is the longest-lived minimum (Table 1 ), with an average lifetime of $62 \mathrm{~ns}$ at $1000 \mathrm{~K}$, increasing to $76 \mu \mathrm{s}$ at $800 \mathrm{~K}$.

Table 1 Kinetic data for Pt@LTA

\begin{tabular}{|c|c|c|c|c|c|c|}
\hline \multirow{2}{*}{ Site } & \multicolumn{4}{|c|}{ Boltzmann Population (\%) } & \multicolumn{2}{c|}{ Occupation Lifetime (s) } \\
\cline { 2 - 7 } & 300 & 500 & 800 & 1000 & 800 & 1000 \\
\hline $\mathrm{S} 1{ }^{*}$ & 99.9 & 99.9 & 98.9 & 97.1 & $2.57 \times 10^{-9}$ & $2.79 \times 10^{-10}$ \\
\hline $\mathrm{S} 1$ & $6.17 \times 10^{-4}$ & $7.48 \times 10-2$ & 0.11 & 0.266 & $2.87 \times 10^{-11}$ & $.63 \times 10^{-12}$ \\
\hline $\mathrm{S} 2_{4}$ & $1.24 \times 10^{-7}$ & $4.52 \times 10-4$ & 0.0452 & $2.07 \times 10-1$ & $7.58 \times 10^{-7}$ & $6.15 \times 10^{-8}$ \\
\hline $\mathrm{S} 2_{6}$ & $2.22 \times 10^{-17}$ & $6.42 \times 10-10$ & $1.00 \times 10-5$ & $2.46 \times 10-4$ & $2.67 \times 10^{-10}$ & $8.85 \times 10^{-11}$ \\
\hline $\mathrm{S} 1 / \mathrm{S} 2_{\alpha}$ & $4.46 \times 10^{-21}$ & $3.88 \times 10-12$ & $4.11 \times 10-7$ & $1.91 \times 10-5$ & $1.03 \times 10^{-11}$ & $6.38 \times 10^{-12}$ \\
\hline $\mathrm{S} 1 / \mathrm{S} 3_{\alpha}$ & $2.1810^{-18}$ & $1.59 \times 10-10$ & $4.18 \times 10-6$ & $1.23 \times 10-4$ & $1.57 \times 10^{-10}$ & $2.93 \times 10^{-11}$ \\
\hline $\mathrm{S} 2 / \mathrm{S}_{\alpha}$ & $1.45 \times 10^{-19}$ & $3.14 \times 10-11$ & $1.52 \times 10-6$ & $5.44 \times 10-5$ & $8.02 \times 10^{-11}$ & $1.73 \times 10^{-11}$ \\
\hline
\end{tabular}




\begin{tabular}{|c|c|c|c|c|c|c|}
\hline $\mathrm{S} 1 / \mathrm{S}_{\alpha}$ & $1.08 \times 10^{-14}$ & $2.63 \times 10-8$ & $1.02 \times 10^{-4}$ & $1.58 \times 10-3$ & $2.82 \times 10^{-11}$ & $1.36 \times 10^{-11}$ \\
\hline
\end{tabular}

\subsection{Adsorbate Interactions with Pt@LTA}

\subsection{1. $\mathrm{Pt}_{1} \mathrm{CO}$}

We investigated the effect of CO incorporation on the Pt@LTA system, via an exhaustive search of the configuration space of $\mathrm{Pt}_{1} \mathrm{CO} @ \mathrm{LTA}$. CO binds to Pt in preference to the zeolite framework $\left(\mathrm{E}_{\mathrm{inc}} \mathrm{CO}=-0.23 \mathrm{eV}\right)$. $\mathrm{CO}$ is observed to dramatically affect the energetics of Pt inside the zeolite. The incorporation energies of PtCO are substantially smaller than Pt: $E_{\text {inc }}$ for the global minimum of PtCO is $-1.38 \mathrm{eV}$, while for Pt it is $-2.39 \mathrm{eV}$. Hence adsorption of CO greatly weakens the binding of Pt to the framework.

The global minimum site for Pt changes from the $\mathrm{S} 1^{*}$ to the $\mathrm{S} 1 / \mathrm{S} 3_{\alpha}$ site upon incorporation of CO. In general, ring sites (S1, S1*, $\mathrm{S}_{4}$ and $\left.\mathrm{S} 2_{6}\right)$ are disfavoured upon $\mathrm{CO}$ adsorption. Several minima, including $\mathrm{S} 1, \mathrm{~S}_{4}$ and $\mathrm{S} 2{ }_{6}$ are no longer stationary points on the potential energy surface. This can be explained by comparison of the electronic structure of Pt@LTA and PtCO@LTA. In the absence of CO, the S1* site has a filled d band, with a band gap of $2.92 \mathrm{eV}$ and a negative charge on Pt. The presence of $\mathrm{CO}$ therefore does not provide any additional electronic stabilisation. When $\mathrm{CO}$ is included, a weak bond is formed between $\mathrm{CO}$ and $\mathrm{Pt}$ (Figure 3). The C-O bond is only moderately strained, from $1.143 \AA$ (in vacuo) to $1.158 \AA$. By contrast, in $\mathrm{S} 1 / \mathrm{S}_{\alpha}$, the formation of a covalent bond via hybridization of the $\mathrm{CO} 5 \sigma$ and the partially filled Pt $5 d$ states fills the Pt $d$ band, giving a highly stabilising $5 d$ shell closing. There is a further hybridization between Pt and the $\mathrm{CO} 2 \pi^{*}$ orbitals. This stronger Pt-CO bonding weakens the C-O bond, which extends to $1.169 \AA$. 


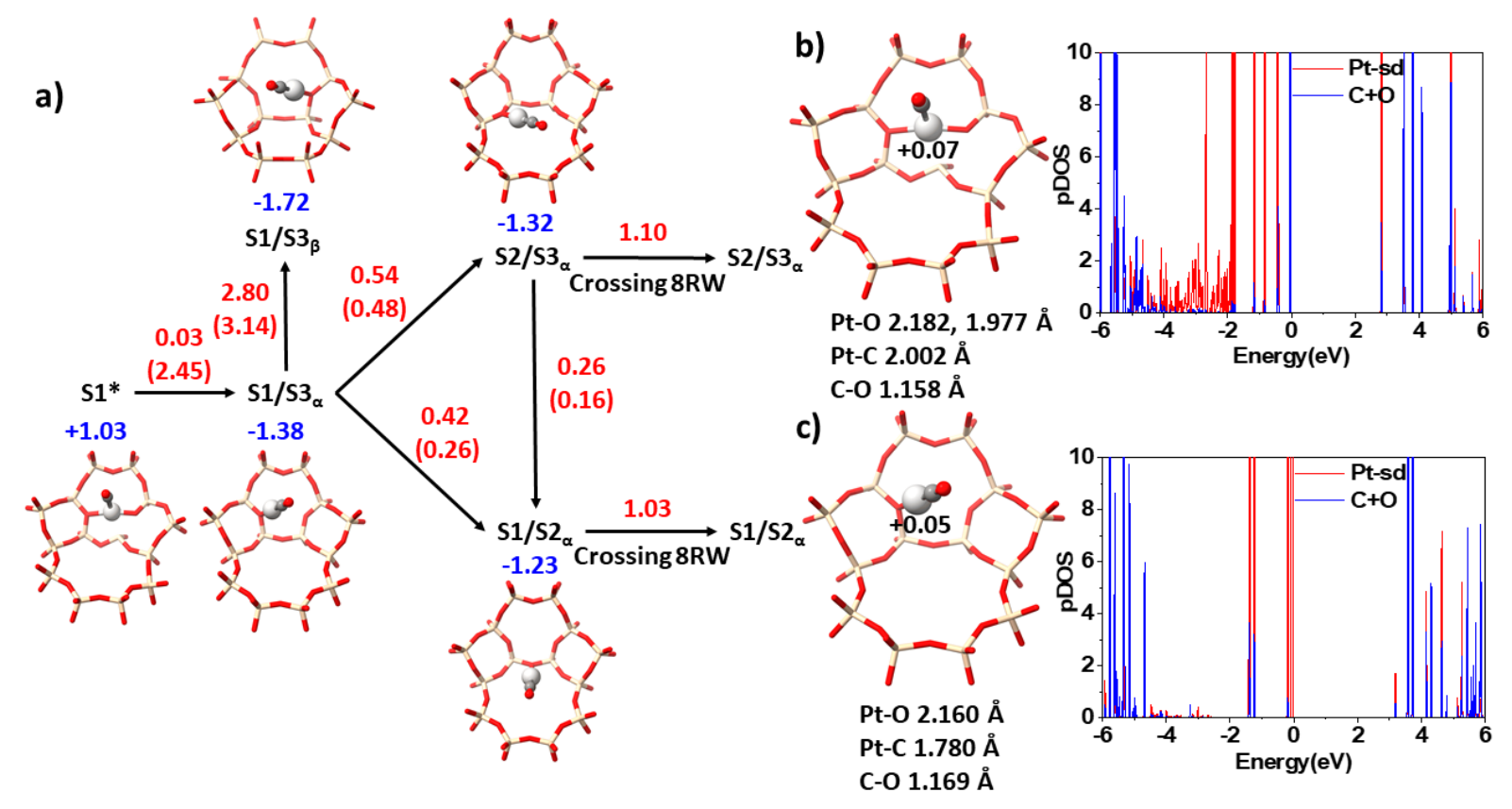

Figure 3: a) Graph representation of the potential energy landscape of PtCO@LTA. Incorporation energies in blue (eV), elementary step barriers in red (eV). Reverse barriers are in parentheses. b)Structure and projected density of states (pDOS) for the $\mathrm{S} 1_{\alpha}{ }^{*}$ site. c) Structure and $\mathrm{pDOS}$ of the $\mathrm{S} 1 / \mathrm{S} 3_{\alpha}$ site.

The $\mathrm{S} 1 / \mathrm{S} 3_{\beta}$ is the only local minimum site for $\mathrm{Pt}$ inside the smaller beta cage. However, $\mathrm{CO}$ is unable to pass through the 6-ring, and the concerted migration of PtCO through the 6-ring has an unfeasibly high barrier of $2.80 \mathrm{eV}$, so PtCO is unable to occupy this site. The loss of ring sites and $\mathrm{S} 1 / \mathrm{S}_{\beta}$ upon $\mathrm{CO}$ adsorption changes the energy landscape for Pt migration. The most favourable route to Pt diffusion between cages is $\mathrm{S} 1 / \mathrm{S} 3_{\alpha} \rightarrow \mathrm{S} 2 / \mathrm{S} 3_{\alpha} \rightarrow \mathrm{S} 2 / \mathrm{S}_{\alpha} \rightarrow \mathrm{S} 1 / \mathrm{S} 3_{\alpha}$. This pathway has an effective barrier of 1.16 eV; substantially lower than for Pt@LTA (1.69 eV). The presence of $\mathrm{CO}$ therefore enhances the diffusion of Pt.

The $\mathrm{S} 1 / \mathrm{S} \mathrm{S}_{\beta}$ site is neglected for the purposes of calculating Boltzmann occupation probabilities, due to its inaccessibility. Table 2 shows that the $S 1_{\alpha}{ }^{*}$ site is also predicted to be unoccupied at all relevant temperatures. For $\alpha$-cage sites, the lowest energy site, $\mathrm{S} 1 / \mathrm{S} 3_{\alpha}$ is dominant, although a non-negligible minority occupation of other sites is predicted. The degree to which the flattened potential energy surface of PtCO affects migration was determined via $\mathrm{kMC}$ simulations. The equilibration time is below the laboratory timescale at $300 \mathrm{~K}(0.02 \mathrm{~s})$ and therefore for all elevated temperatures, $0.15 \mathrm{~ms}$ at $500 \mathrm{~K}$, and $0.99 \mu \mathrm{s}$ at 800 $\mathrm{K}$. By comparing with $\mathrm{Pt}$ at the highest common temperature $(800 \mathrm{~K})$, the presence of $\mathrm{CO}$ 
speeds up equilibration by four orders of magnitude. The occupation lifetimes show that the lowest energy site, $\mathrm{S} 1 / \mathrm{S}_{\alpha}$ has the longest lifetime at all temperatures, which at room temperature is approximately $1 \mathrm{~ms}$. At $800 \mathrm{~K}$, the lifetime of the global minimum is $30 \mathrm{~ns}$, which is three orders of magnitude shorter than the longest-lived Pt site, in the 8-ring (S24).

Table 2 Kinetic data forPtCO@LTA.

\begin{tabular}{|c|c|c|c|c|c|c|}
\hline Site & \multicolumn{2}{|c|}{ Boltzmann Population (\%) } & \multicolumn{2}{c|}{ Occupation Lifetime (s) } \\
\hline & 300 & 500 & 800 & 300 & 500 & 800 \\
\hline $\mathrm{S} 1 \alpha^{*}$ & 0 & 0 & 0 & 0 & 0 & 0 \\
\hline $\mathrm{S} 1 \mathrm{~S} 3_{\alpha}$ & 90.8 & 78.2 & 65.3 & $9.08 \times 10^{-4}$ & $1.30 \times 10^{-6}$ & $3.02 \times 10^{-8}$ \\
\hline $\mathrm{S} 2 \mathrm{~S}_{\alpha}$ & 8.91 & 19.4 & 27.3 & $1.88 \times 10^{-6}$ & $3.34 \times 10^{-8}$ & $3.36 \times 10^{-9}$ \\
\hline $\mathrm{S} 1 \mathrm{~S} 2_{\alpha}$ & 0.27 & 2.40 & 7.40 & $3.83 \times 10^{-8}$ & $3.00 \times 10^{-9}$ & $6.62 \times 10^{-10}$ \\
\hline
\end{tabular}

\subsection{2 $\mathrm{Pt}_{1}(\mathrm{CO})_{\mathrm{m}}$}

The role of CO loading on the stability of Pt in LTA was considered, by adsorption of multiple CO molecules to Pt@LTA and Pt(g). For both isolated and zeolite-encapsulated Pt, the limiting number of CO molecules $(\mathrm{m})$ which associate with Pt is four. The complexes in the zeolite are structurally similar to those in vacuo (Figure 4). $\mathrm{Pt}(\mathrm{CO})_{2}$ is a bent linear complex, $\mathrm{Pt}(\mathrm{CO})_{3}$ is a trigonal planar structure and $\mathrm{Pt}(\mathrm{CO})_{4}$ adopts a tetrahedral configuration. The adsorption energy of $\mathrm{CO}$ is substantially reduced in the encapsulated complexes with respect to the vacuo complexes (Table 3). Furthermore, the adsorption energy per CO decreases monotonically with increasing $\mathrm{m}$ for both vacuum and encapsulated $\mathrm{Pt}(\mathrm{CO})_{\mathrm{m}}$ complexes. The weakening Pt$\mathrm{CO}$ bonds are reflected in the increasing average $\mathrm{Pt}-\mathrm{C}$ and decreasing average $\mathrm{C}-\mathrm{O}$ bond lengths as the loading of CO molecules increases.

Table 3 Energetic data for $\mathrm{Pt}(\mathrm{CO}) \mathrm{m}$ complexes. Values in parentheses are for corresponding vacuum complexes.

\begin{tabular}{|l|l|l|l|l|l|}
\hline $\mathbf{n}$ & Eads $(\mathbf{e V}) / \mathbf{C O}$ & $\mathbf{E}_{\text {inc }}(\mathbf{e V})$ & $\mathbf{q}(\mathbf{P t})\left(\mathbf{e}^{-}\right)$ & $\langle r(\mathrm{Pt}-\mathrm{C})\rangle(\AA \AA)$ & $\langle r(\mathrm{C}-\mathbf{0})\rangle(\AA \AA)$ \\
\hline 1 & $-2.95(-3.84)$ & -1.38 & $+0.05(+0.03)$ & $1.780(1.757)$ & $1.169(1.167)$ \\
\hline 2 & $-2.18(-3.12)$ & -0.63 & $+0.16(+0.16)$ & $1.878(1.833)$ & $1.159(1.157)$ \\
\hline 3 & $-1.80(-2.46)$ & -0.74 & $+0.32(+0.29)$ & $1.922(1.924)$ & $1.158(1.158)$ \\
\hline 4 & $-1.51(2.04)$ & -0.84 & $+0.34(+0.33)$ & $1.954(1.954)$ & $1.156(1.156)$ \\
\hline
\end{tabular}


The most significant effect of CO loading on encapsulated Pt is to detach the Pt atom from the framework. For $n>1$, the $\mathrm{Pt}(\mathrm{CO})_{n}$ complex becomes volatile, occupying the free space in the $\alpha$-cage, with no covalent bonds to the framework. The powerful effect of $\mathrm{CO}$ in dispersing Pt clusters into smaller, carboxylated units is well-established in the literature, both on oxide surfaces and in zeolites. ${ }^{50-54}$ The global minimum configurations for all volatile complexes involve one CO molecule occupying the centre of the 8-ring. This is a dispersion-driven effect, with no formation of covalent bonds or strain of the 8-ring.

The incorporation energies of the $\mathrm{Pt}(\mathrm{CO})_{\mathrm{m}}$ complexes show the preference for incorporation of the entire complex into the zeolite. $E_{\text {inc }}$ is therefore a combination of energetic contributions, including binding energy to the framework, dispersive stabilisation in the pore, and steric strain due to confinement in the alpha cage. The total incorporation energy decreases in magnitude from $\mathrm{PtCO}$ to $\mathrm{Pt}(\mathrm{CO})_{2}$, which is consistent with the loss of the Pt-O framework bond. $E_{\text {inc }}$ then increases in magnitude from $\mathrm{Pt}(\mathrm{CO})_{2}$ to $\mathrm{Pt}(\mathrm{CO})_{4}$, as additional $\mathrm{CO}$ molecules stabilise the volatile complex in the pore. For all CO loadings, $\mathrm{E}_{\text {inc }}$ is negative, which implies that overall, the loss of framework binding is overcome by the gain in favourable dispersive interactions between $\mathrm{Pt}(\mathrm{CO})_{\mathrm{m}}$ and the zeolite framework.

a)

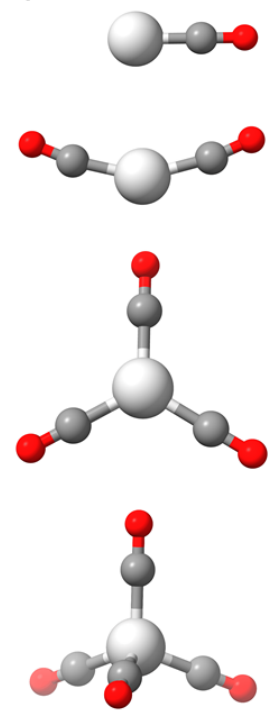

b)

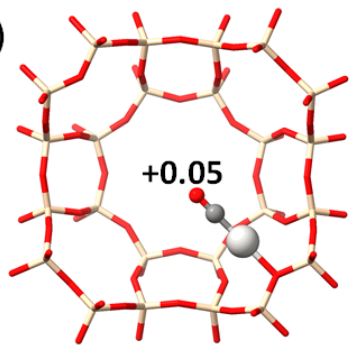

PtCO

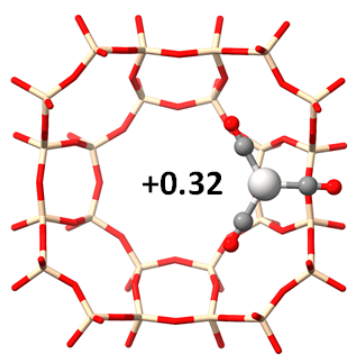

$\mathrm{Pt}(\mathrm{CO})_{3}$

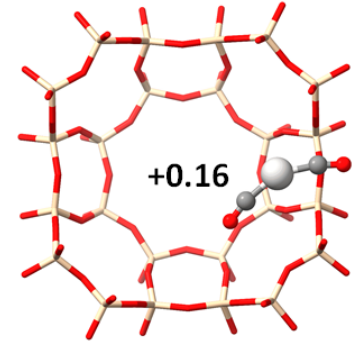

$\mathrm{Pt}(\mathrm{CO})_{2}$

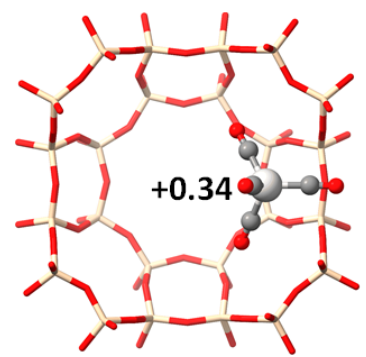

$\mathrm{Pt}(\mathrm{CO})_{4}$

Figure 4: Structures of global minimum Pt $(\mathrm{CO})_{n}$ complexes $(n<5)$ in a)vacuo, b)LTA (Pt charge is labelled). 
$A b$ initio dynamics simulations were performed for $\mathrm{Pt}(\mathrm{CO})_{\mathrm{m}}$, in order to determine whether any atom trapping was present, despite the lack of framework-association on the potential energy surface. 10 ps equilibration simulations were run at $450 \mathrm{~K}$. In all cases, except PtCO, which is bound to the framework, the complexes moved freely inside the $\alpha$-cage, and did not transfer between cages on the timescale of the simulation. No bond formation between complex and framework was observed. For $n=1,2$ and 3, the complex was stable, while $\mathrm{Pt}(\mathrm{CO})_{4}$ exhibited transient dissociation and re-association of one $\mathrm{CO}$ molecule, which is consist with the findings that $\mathrm{Pt}(\mathrm{CO})_{4}$ and $\mathrm{Pd}(\mathrm{CO})_{4}$ are not stable at room temperature. ${ }^{55-56}$

\subsection{3. $\mathrm{Pt}_{\mathrm{n}}(\mathrm{CO}) \mathrm{m}$}

In order to observe the effect of adsorbates on the association and dissociation of Pt clusters, we calculated the dissociation energies according to various dissociation channels for $\mathrm{Pt}_{5}(\mathrm{CO})_{\mathrm{m}}(\mathrm{m}=1-6)$ in vacuo and encapsulated within LTA (Figure 5). Clusters were generated via global optimisation in the vacuum phase, and transferred to the zeolite pore, followed by local structure relaxation. For CO loadings up to $m=5$, the smallest dissociation energy in the zeolite was found for the process $\mathrm{Pt}_{5}(\mathrm{CO})_{\mathrm{m}} \rightarrow \mathrm{Pt}_{4}(\mathrm{CO})_{\mathrm{m}-1}+\mathrm{PtCO}$. This implies that the loss of a PtCO unit from the larger cluster is easier than CO detachment, or the loss of a single metal atom.

The dissociation energy to produce PtCO is consistent for $m=1-4$, between +1.94 and +2.08 $\mathrm{eV}$. This value decreases sharply at $\mathrm{n}=5\left(\mathrm{E}_{\text {diss }}=+1.48 \mathrm{eV}\right)$. The reduction in energetic cost at high CO loading is likely due to the release of steric strain on the highly covered Pt cluster. The same trend is observed for the $\mathrm{Pt}_{5}(\mathrm{CO})_{\mathrm{m}} \rightarrow \mathrm{Pt}_{5}(\mathrm{CO})_{\mathrm{m}-1}+\mathrm{CO}$ channel. However, the weak adsorption of $\mathrm{CO}$ to the zeolite framework ensures that this channel is uncompetitive until $m=6$, at which point, the loss of CO becomes the energetically favourable channel. The channel $\mathrm{Pt}_{5}(\mathrm{CO})_{\mathrm{m}} \rightarrow \mathrm{Pt}_{4}(\mathrm{CO})_{\mathrm{m}}+\mathrm{Pt}$ is uncompetitive over the full range of $\mathrm{m}$, despite the strong binding of the bare Pt atom to the framework. Other channels leading to the release of $\mathrm{Pt}(\mathrm{CO})_{\mathrm{m}}(\mathrm{m}>1)$ are uncompetitive due to the loss of binding to the framework of such species. Hence, PtCO is likely to be the species which detaches and migrate in the framework during dissociation and re-association processes. 
By contrast, the vacuum clusters do not show the same dissociation energy trends. The lowest energy channel is $\mathrm{CO}$ loss $\left(\mathrm{Pt}_{5}(\mathrm{CO})_{\mathrm{m}} \rightarrow \mathrm{Pt}_{5}(\mathrm{CO})_{\mathrm{m}-1}+\mathrm{CO}\right)$, as the dominant energetic contribution to vacuum cluster is the Pt-Pt bonding. Similar findings are observed for $\mathrm{Pt}_{4}(\mathrm{CO})_{\mathrm{m}}$ $(m=1-4)$. Hence, the zeolite framework is crucial to the dissociation behaviour of the cluster; providing a necessary environment for the stabilisation of small PtCO fragments, which in turn are more mobile than Pt atoms.

a)

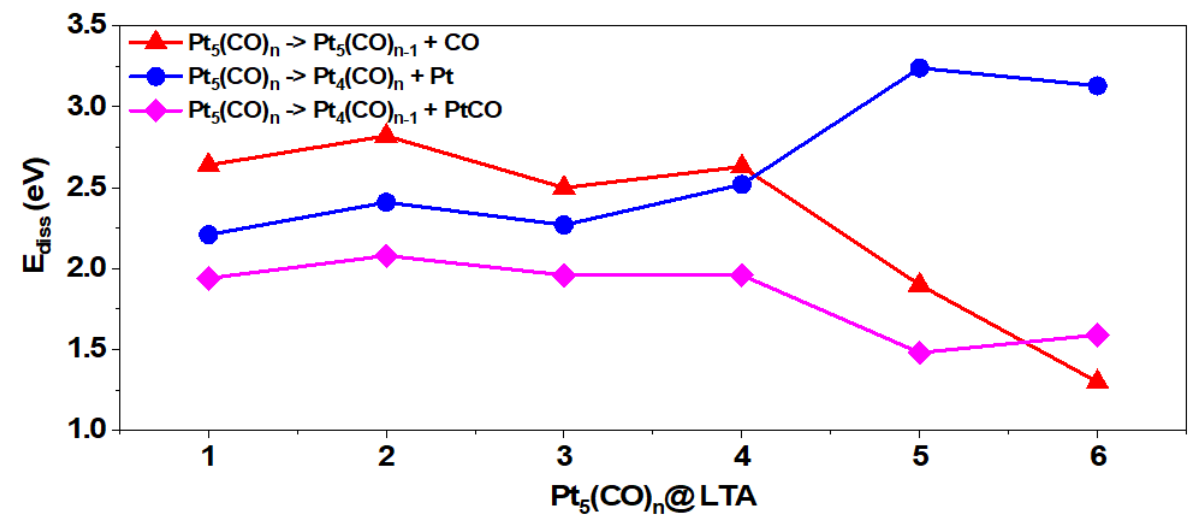

b)

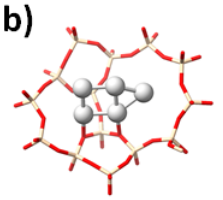

$\mathrm{Pt}_{5} @ L T A$

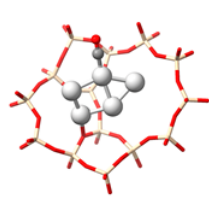

$\mathrm{Pt}_{5}$ CO@LTA

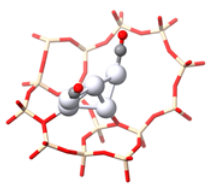

$\mathrm{Pt}_{5}(\mathrm{CO})_{2} @ \mathrm{LTA}$

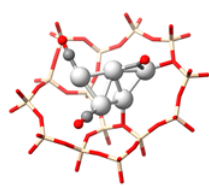

$\mathrm{Pt}_{5}(\mathrm{CO})_{3} @ \mathrm{LTA}$

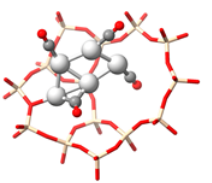

$\mathrm{Pt}_{5}(\mathrm{CO})_{4} @ \mathrm{LTA}$

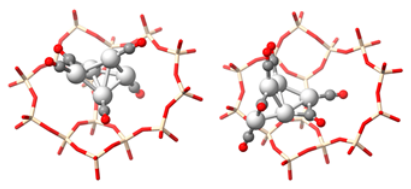

$\mathrm{Pt}_{5}(\mathrm{CO})_{5} @ \mathrm{LTA} \quad \mathrm{Pt}_{5}(\mathrm{CO})_{6} @ \mathrm{LTA}$

Figure 5 a)Dissociation energies for various channels from Pt5(CO $)_{n}$ encapsulated in the $\alpha$-cage of LTA, b) initial structures of the CO-covered $\mathrm{Pt}_{5}$ clusters.

\subsection{4. $\mathrm{PtH}_{2}$}

The introduction of $\mathrm{H}_{2}$ to Pt atoms in LTA leads to dissociative adsorption and the formation of framework-associated $\mathrm{PtH}_{2}$ species. The incorporation energies of $\mathrm{PtH}_{2}$ are smaller than for both PtCO and Pt; $E_{\text {inc }}$ for the global minimum site (S1) is $-1.08 \mathrm{eV}$ (Figure 6). The $\mathrm{S}^{*}$ site is unable to adsorb $\mathrm{H}_{2}$, and is therefore substantially destabilised upon $\mathrm{H}_{2}$ incorporation. This can be observed in the electronic structure (Figure 6). The Pt d band is filled in the Pt S1* site, and $\mathrm{H}_{2}$ is unable to form a covalent bond. The hydrogenic states remain unhybridized with Pt. The $\mathrm{H}-\mathrm{H}$ bond is lengthened from $0.750 \AA$ to $0.757 \AA$, while the minimum Pt-H distance is 
$2.759 \AA$ A. By contrast, $\mathrm{H}_{2}$ adsorbs to Pt in the $\mathrm{S} 1 / \mathrm{S}_{\alpha}$ site (Figure 6). Pt d states hybridize with $\mathrm{H}$ 1s states in a band between -3 to $-4 \mathrm{eV}$, forming a covalent bond which fills the Pt $\mathrm{d}$ band, forming a stable complex which remains bound to the framework. The $\mathrm{H}-\mathrm{H}$ bond is broken, forming two Pt-H bonds of length 1.531/1.532 A.

a)
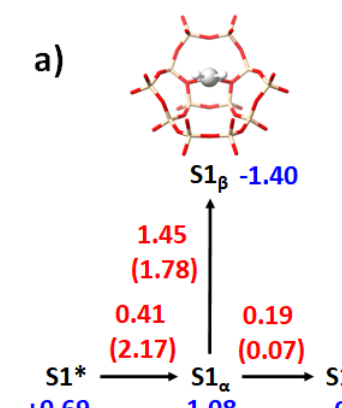

$+0.69$

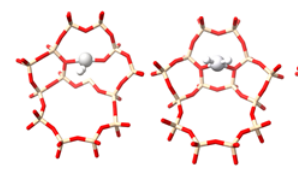

S3-1. $\frac{0.48}{\text { Crossing 8RW }}$ S2-1

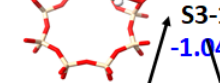

\subsection{8}

$(0.26)$

(0.26)

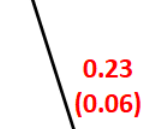

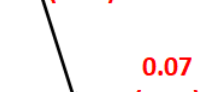

$\mathrm{S} 1 / \mathrm{S} 3_{\alpha} \underset{(0.10)}{\longrightarrow} \mathrm{S} 2 / \mathrm{S3}_{\alpha} \stackrel{(0.24)}{\longrightarrow} \mathrm{s3-2}$
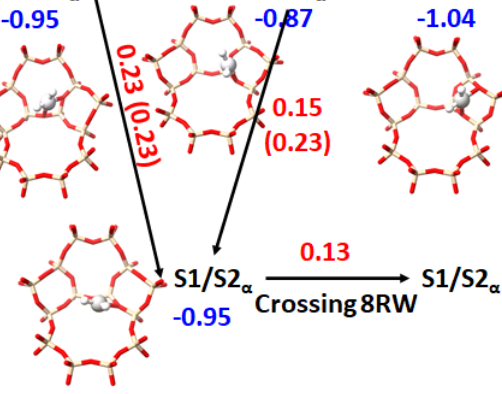

b)

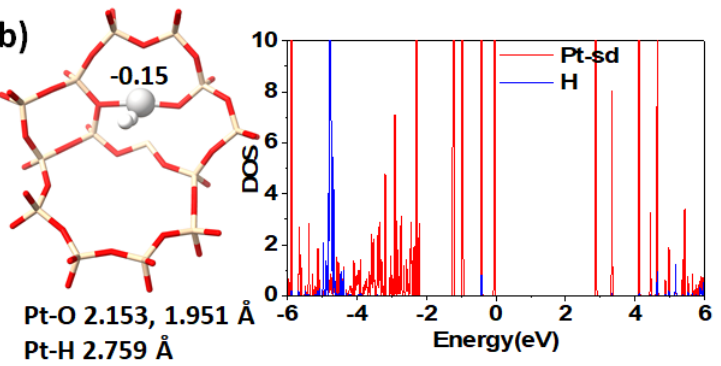

Pt-H $2.759 \AA$ H-H $0.757 \AA$

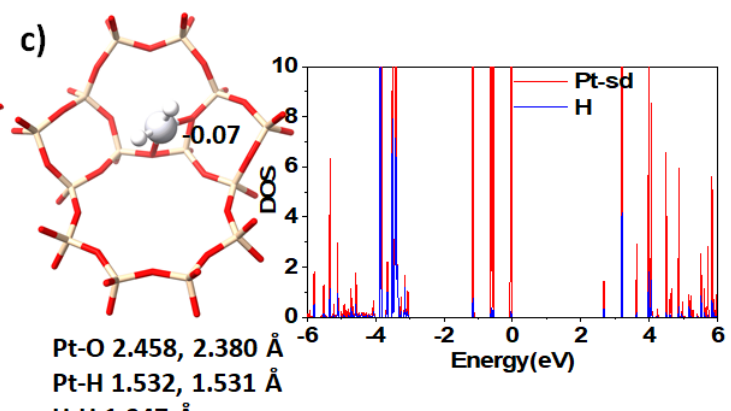

c)

H-H $1.947 \AA$

Figure 6: a) Graph representation of the potential energy landscape of PtH $\mathrm{t}_{2} @ \mathrm{LTA}$. Incorporation energies in blue (eV), elementary step barriers in red (eV). Reverse barriers are in parentheses. b) Structure and projected density of states (pDOS) for the $\mathrm{S}^{*}$ site. c) Structure and projected density of states (pDOS) for the $\mathrm{S} 1 / \mathrm{S} 3 \alpha$ site.

Ring sites are available to $\mathrm{PtH}_{2}$, including $\mathrm{S} 1$, and two iso-energetic rotational isomers at the S3 site, which lie over the 4-ring, denoted S3-1 and S3-2. These ring sites differ from those available to $\mathrm{Pt}$, as they no longer lie in the plane of the ring, owing to the steric hindrance of the additional hydrogen atoms. The $S 1_{\beta}$ site, inside the sodalite $(\beta)$ cage is present for $\mathrm{PtH}_{2}$, but occupation is severely hindered by a high barrier of $1.45 \mathrm{eV}$ from the $\mathrm{S} 1_{\alpha}$ site. Overall, the energy landscape for Pt migration is flattened in the presence of $\mathrm{H}_{2}$. Migration barriers among and between $\alpha$-cage sites are considerably lower for $\mathrm{PtH}_{2}$ than for $\mathrm{PtCO}$ or $\mathrm{Pt}$, with a maximum barrier height of $0.48 \mathrm{eV}$ for a ring-crossing step between S3-1 and S3-1 via the 8- 
ring. The lowest effective barrier for a diffusion through the pore system is $0.52 \mathrm{eV}$ and proceeds via the route $\mathrm{S} 1_{\alpha} \rightarrow \mathrm{S} 1 / \mathrm{S} 3_{\alpha} \rightarrow \mathrm{S} 3-1_{\alpha} \rightarrow \mathrm{S} 3-1_{\alpha} \rightarrow \mathrm{S} 1 / \mathrm{S} 3_{\alpha} \rightarrow \mathrm{S} 1_{\alpha}$. The incorporation of $\mathrm{H}_{2}$ removes the special stabilisation of Pt in the 6-ring, while activating diffusion between pores. Given the inaccessibility of the $S 1_{\beta}$ site, it was excluded from the site list for calculation of Boltzmann probabilities, and thus, from the kMC simulation. Among the accessible sites, the flattened energy landscape is manifested in the non-negligible occupation of S3-1 and S3-2 sites in addition to the $\mathrm{S} 1_{\alpha}$. At $800 \mathrm{~K}$, the maximum occupation probability is only $40 \%$.

The kinetics of $\mathrm{PtH}_{2}$ migration were examined via $\mathrm{kMC}$ simulations. The equilibration time is $0.2 \mathrm{~ms}$ at $300 \mathrm{~K}, 49 \mu \mathrm{s}$ at $500 \mathrm{~K}$, and $0.5 \mu \mathrm{s}$ at $800 \mathrm{~K}$. Therefore, sampling of configurational space is fast, and the migration necessary for growth is able to occur far below the laboratory timescale. The occupation lifetimes of sites range from the nanosecond to the picosecond scale at all temperatures, with the minority species S3-2 the longest-lived, from $173 \mathrm{~ns}$ at 300 $\mathrm{K}$ to $0.2 \mathrm{~ns}$ at $800 \mathrm{~K}$. This maximum lifetime is shorter than that of $\mathrm{PtCO}$, for which the global minimum is a deeper kinetic trap.

Table 4 Kinetic data for $\mathrm{PtH}_{2} @$ LTA.

\begin{tabular}{|l|l|l|l|l|l|l|}
\hline \multirow{2}{*}{ Site } & \multicolumn{2}{|l}{ Boltzmann Population (\%) } & \multicolumn{2}{l}{ Occupation Lifetime (s) } \\
\cline { 2 - 7 } & 300 & 500 & 800 & 300 & 500 & 800 \\
\hline S1 ${ }^{*}$ & $2.71 \times 10^{-28}$ & $1.19 \times 10-16$ & $3.79 \times 10-10$ & 0 & 0 & 0 \\
\hline S1 $\alpha$ & 69.5 & 52.8 & 40.5 & $2.50 \times 10^{-8}$ & $7.93 \times 10^{-10}$ & $9.43 \times 10^{-11}$ \\
\hline S1/S3 $\alpha$ & 0.45 & 2.58 & 6.14 & $2.33 \times 10^{-10}$ & $4.14 \times 10^{-11}$ & $1.10 \times 10^{-11}$ \\
\hline S3-1 & 14.8 & 20.8 & 22.7 & $8.93 \times 10^{-8}$ & $1.34 \times 10^{-9}$ & $1.01 \times 10^{-10}$ \\
\hline S2/S3 $\alpha$ & 0.02 & 0.40 & 1.92 & $8.50 \times 10^{-11}$ & $1.67 \times 10^{-11}$ & $5.33 \times 10^{-12}$ \\
\hline S1/S2 $\alpha$ & 0.45 & 2.58 & 6.14 & $2.35 \times 10^{-9}$ & $1.64 \times 10^{-10}$ & $2.70 \times 10^{-11}$ \\
\hline S3-2 & 14.8 & 20.8 & 22.7 & $1.73 \times 10^{-7}$ & $2.54 \times 10^{-9}$ & $1.95 \times 10^{-10}$ \\
\hline
\end{tabular}

\subsection{Encapsulation of Au into Zeolite LTA}

\subsubsection{Au 1 @LTA}

In order to determine the effect of the electronic structure of noble metals on their behaviour upon encapsulation, we replaced platinum with gold. Isolated Au exhibits a d10s1 electronic configuration, and therefore retains the open s shell, but unlike Pt, has no capacity for 
donation of electrons from framework oxygen atoms or adsorbate molecules into the metal $d$ band. Upon encapsulation, the DOS reveals that the electronic structure is not significantly perturbed by the presence of the framework (Figure 7a). The s states remain unfilled, with a 6s orbital around $0.6 \mathrm{eV}$ above the Fermi level. Thus, interactions between $\mathrm{Au}$ and the framework do not induce a stabilising shell closing effect as was observed for Pt.

Global structure optimisation of $\mathrm{Au}_{1} @$ LTA reveals that $\mathrm{Au}$ interacts weakly with the framework, primarily through dispersion. There are only four stable sites for Au in LTA: $S 1_{\alpha}$, $S 1_{\beta}, S 2$ and $S 3$. These sites, all of which are in the centre of rings, do not involve the formation of covalent bonds, and therefore have small incorporation energies $(-0.38,-0.58,-0.41$ and $0.34 \mathrm{eV}$, respectively). The occupation of 6-ring sites is preferred for both $\mathrm{Pt}$ and $\mathrm{Au}$, although the nature and strength of the interactions are different. The minimum Au-O distances are3.229, 3.469, 3.501, $3.335 \AA$, for $S 1_{\beta}, \mathrm{S} 2$ and $\mathrm{S} 3$, respectively, which indicate a weak interaction, in contrast with the strong binding of Pt@LTA.

Migration barriers between sites in the $\alpha$-cage $\left(\mathrm{S}_{\alpha}, \mathrm{S} 2\right.$ and $\left.\mathrm{S} 3\right)$ are all below $0.1 \mathrm{eV}$. Therefore, $\mathrm{Au}$ atoms may diffuse unhindered through the pore system of siliceous LTA via $\alpha$-cages connected by 8-rings. The global minimum site $\left(\mathrm{S}_{\beta}\right)$ is connected to all other sites by a migration route through the 6-ring window. This migration is severely hindered, proceeding via a transition state in which Au lies in the plane of the unbroken 6-ring, with a barrier of $1.24 \mathrm{eV}$ from $\mathrm{S} 1_{\beta} \rightarrow \mathrm{S} 1_{\alpha}(1.04 \mathrm{eV}$ for the reverse step). This step represents a significant departure from the behaviour of Pt in LTA. While the plane of the 6-ring window is the site of the two most stable minima for Pt ( $\mathrm{S} 1$ and $\mathrm{S} 1^{*}$ ), it is the highest energy transition state for $\mathrm{Au}$ (Figure 7b). Hence, the migration kinetics of Au in LTA will consist of fast diffusion through the pore system, with occasional trapping in the $\beta$-cage for long timescales. The lack of framework interaction and small migration barriers suggest a poor resistance to sintering. 

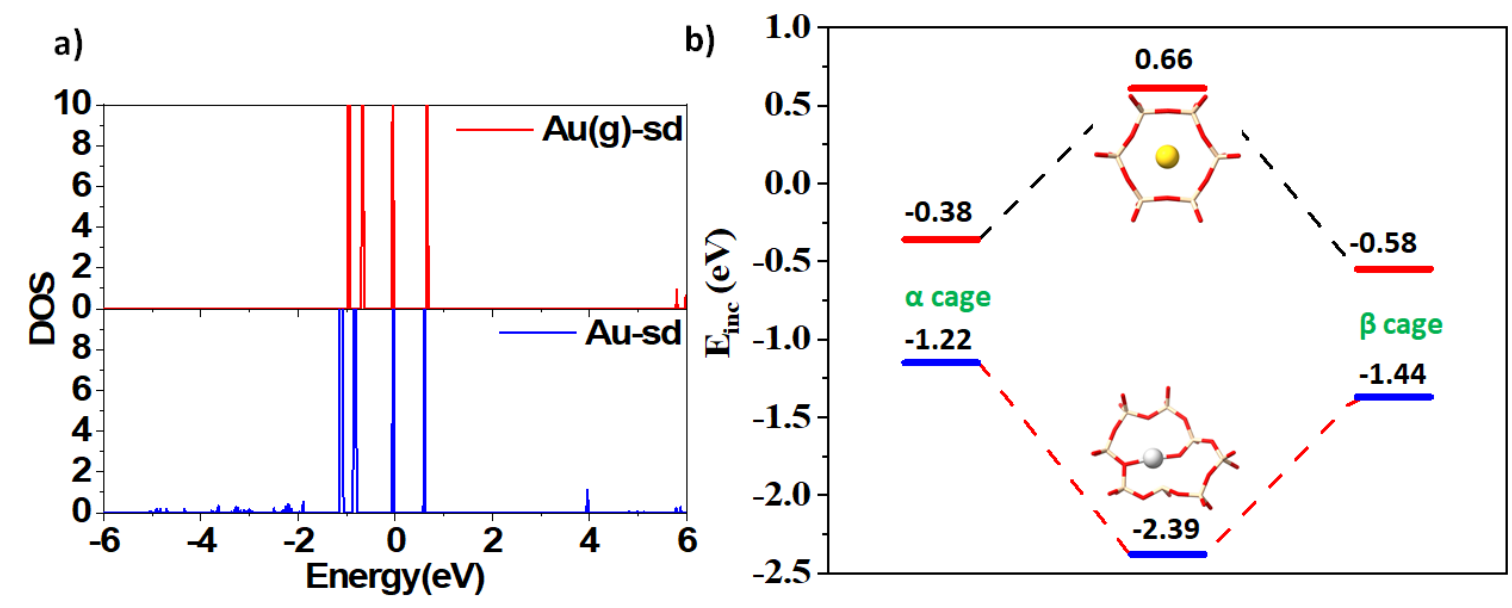

Figure 7: a) The pDOS for an isolated Au atom in vacuo (top) and inside the LTA pore (bottom), b)The incorporation energies adjacent structures in the $\alpha$ and $\beta$ cages of Pt@LTA and Au@LTA.

\subsubsection{Au-X@LTA (X=CO, $\left.\mathrm{H}_{2}\right)$}

The effect of adsorbates on the energetics and structures of Au@zeolite configurations was probed using $\mathrm{CO}$ and $\mathrm{H}_{2}$ molecules. We find that the $\mathrm{Au}(\mathrm{CO})_{\mathrm{m}}$ complexes exhibit somewhat different geometries to the $\mathrm{Pt}(\mathrm{CO})_{\mathrm{n}}$ complexes. For $\mathrm{m}=1$, the $\mathrm{PtCO}$ complex remains attached to the framework, while AuCO shows no framework attachment, and adopted a bent structure. This has previously been observed in calculations of vacuo AuCO complexes. ${ }^{57-58}$ For $\mathrm{m}=2, \mathrm{Pt}(\mathrm{CO})_{2}$ has a bent-linear geometry, while $\mathrm{Au}$ is linear. For $\mathrm{m}=3$, the structures are similar. However, for all cases, the adsorption energies are significantly lower to Au than Pt. $\mathrm{AuCO}, \mathrm{Au}(\mathrm{CO})_{2}$ and $\mathrm{Au}(\mathrm{CO})_{3}$ all adopt configurations in which the $\mathrm{CO}$ molecule occupies the 8-ring, and no strong interactions are formed between the metal site and the framework (Figure 8). Unlike in the case of $\mathrm{Pt}(\mathrm{CO})_{\mathrm{m}}$, the adsorption energy of $\mathrm{CO}$ is not significantly reduced upon confinement within the pore (Table 5). No local minimum was obtained for the $\mathrm{Au}(\mathrm{CO})_{4}$ complex, which implies that the $\mathrm{Au}$ atom has a smaller capacity for CO adsorption than Pt. 
Table 5 Energetic data for $\mathrm{Au}(\mathrm{CO})_{\mathrm{m}}$ complexes. Values in parentheses are for corresponding vacuum complexes.

\begin{tabular}{|l|l|l|l|l|l|}
\hline $\mathbf{n}$ & $\mathbf{E}_{\text {ads }}(\mathbf{e V}) / \mathbf{C O}$ & $\mathbf{E}_{\text {inc }}(\mathbf{e V})$ & $\mathbf{q}(\mathbf{P t})\left(\mathbf{e}^{-}\right)$ & $<\mathrm{r}(\mathrm{Au}-\mathrm{C})>(\AA)$ & $<\mathrm{r}(\mathrm{C}-\mathrm{O})>(\AA \AA)$ \\
\hline 1 & $-0.90(-0.84)$ & -0.69 & $+0.02(-0.05)$ & $1.969(1.970)$ & $1.160(1.162)$ \\
\hline 2 & $-1.01(-1.17)$ & -0.55 & $+0.29(+0.29)$ & $1.919(1.919)$ & $1.166(1.166)$ \\
\hline 3 & $-0.80(-0.92)$ & -0.72 & $+0.33(+0.32)$ & $1.973(1.973)$ & $1.160(1.160)$ \\
\hline
\end{tabular}

Au forms weak complexes with $\mathrm{H}_{2}$, with long $\mathrm{Au}-\mathrm{H}$ bond lengths of greater than $2 \AA$ (c.f. 1.53 $\AA$ for $\mathrm{PtH}_{2}$ ). The $\mathrm{H}-\mathrm{H}$ bonds are increased negligibly, from $0.750 \AA$ to $0.777,0.778$ and 0.779 $\AA ̊$ in S2, S1 and S3, respectively.

a)
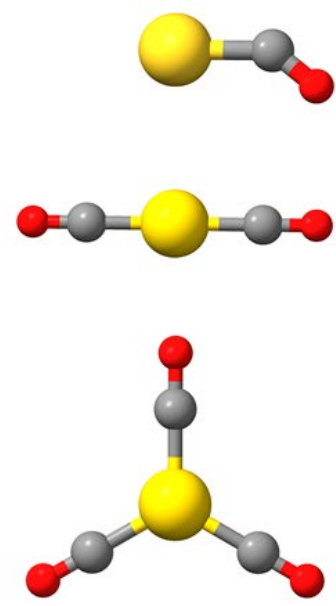

b)

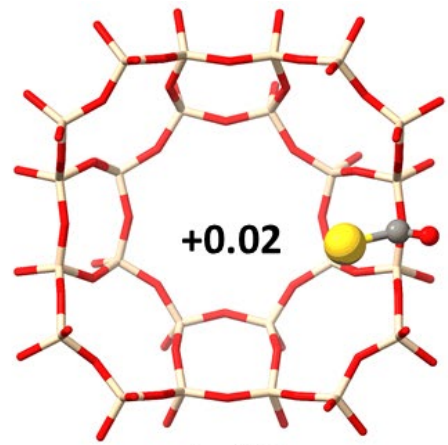

AuCO

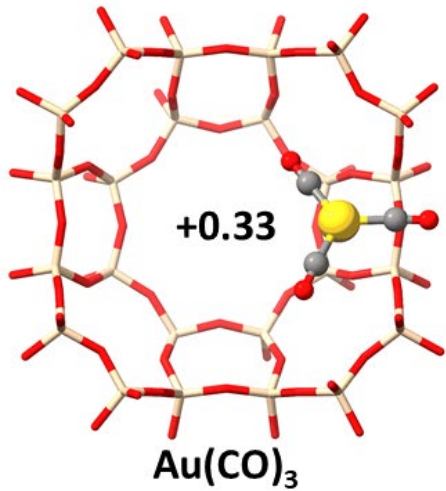

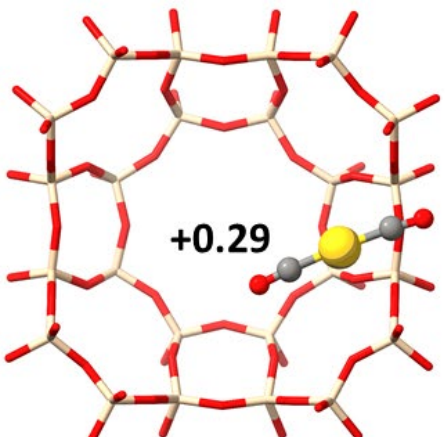

$\mathrm{Au}(\mathrm{CO})_{2}$

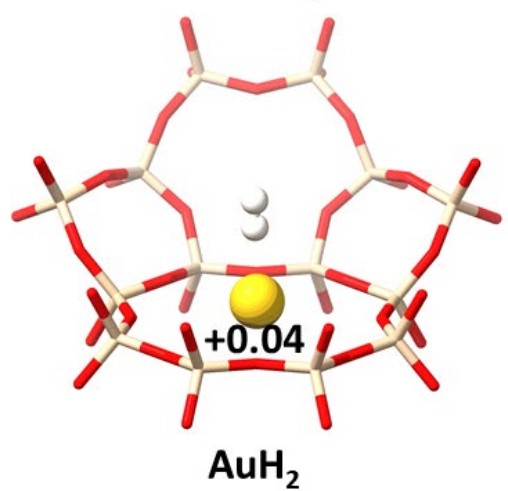

Figure 8 Structures of global minima for $A u(C O)_{n}(n<4)$ in a)vacuo, b)LTA, in addition to the global minimum for AuH ${ }_{2} @$ LTA (bottom right). 


\section{Discussion}

$\mathrm{CO}$ is known to accelerate the sintering of zeolite-encapsulated metal (M) particles, while oxidants, such as $\mathrm{O}_{2} / \mathrm{NO}$ reverse the process, although the mean by which the sintering is enhanced remain unclear. These findings are primarily derived from aluminium-containing frameworks. In such zeolites, the initial binding sites of single $\mathrm{M}$ atoms are at Al sites. This has been shown in the case of the metal atom (M) acting as a charge-compensating cation via ion-exchange, in which case the oxidation state may be $\mathrm{M}^{+}$or $\mathrm{M}^{2+}$, depending on whether isolated or paired Al-sites are present. We have shown in our recent work that isolated Al sites lead to the trapping of $\mathrm{Pt}$ as $\mathrm{Pt}^{+}$, even without the replacement of the charge compensating ion. Pt inserts into the $\mathrm{O}-\mathrm{H}$ bond at a Brønsted site, forming a $\mathrm{PtH}^{+}$moiety. Therefore, in the presence of framework Al, Pt is likely to always be oxidized to some degree. Hence, the role of oxidisers such as $\mathrm{O}_{2} / \mathrm{NO}$, or reductants such as $\mathrm{CO} / \mathrm{H}_{2}$ is different from the case in the current study, in which a purely siliceous zeolite form is the encapsulating medium. Despite the difference in the type of binding site available for M-framework bonding in siliceous frameworks, and therefore the resulting oxidation state of the metal atom, we find that both $\mathrm{H}_{2}$ and $\mathrm{CO}$ assist in the weakening of framework bonding, and the reduction of migration barriers. In the case of $\mathrm{H}_{2}$, these barriers are sufficiently low for facile migration at room temperature.

$\mathrm{CO}$ is also known to weaken Pt-Pt bonds in Pt clusters supported on metal oxide films, and therefore may aid, counter-intuitively, in the dissociation of Pt clusters. We observe that CO does indeed reduce the energetic cost to dissociation of clusters, by providing channels which release Pt atoms in the form of PtCO. This dissociation channel is more facile than for single Pt atoms, and is less endothermic than for vacuum clusters. This promotion of PtCO dissociation upon encapsulation into the zeolite is an example of the strong metal support interaction (SMSI) effect, which is well established for two-dimensional surface supports.

PtCO represents an energetic compromise between the high stabilisation of the isolated Pt atom in the framework (naked $\mathrm{Pt}_{1}$ in $\mathrm{S}^{*}$ is the most stable configuration) and less stable, volatile species which are too bulky to pass through the 8-ring $\left(\mathrm{PtCO}_{n}(n>2)\right)$. The intermediate 
strength of PtCO binding to the framework allows the species to move through the pore system, with reduced barriers with respect to $\mathrm{Pt}$, and bind favourably to larger clusters without destabilising them through overburdening with $\mathrm{CO}$.

Ostwald ripening mechanisms involve the migration of small clusters/atoms to connect with larger clusters. These processes often involve detachment from small clusters before migration to locate larger particles. PtCO is the complex with the smallest dissociation energy from larger clusters inside the zeolite, and is therefore the most likely candidate for such processes. It should be noted however, that detachment of any kind is highly endothermic ( 2 $\mathrm{eV})$, and at the temperatures required to reach such energies, cluster mobility is likely to be high. Hence, one cannot rule out the migration of small clusters as a major component of sintering processes. Such a possibility requires the simulation of long timescale dynamics of Pt clusters, which is the subject of an ongoing investigation.

The difference in the strength and type of bonding between metal and framework implies that $\mathrm{Au}$ and Pt represent two distinct regimes. For $\mathrm{Au}$, the zeolite is an inert framework which represents a physical limit to migration and growth. For Pt, the zeolite is a chemically reactive medium, which is traversed via bond breaking and forming steps. For both Pt and Au, the $\alpha$ and $\beta$ cages are separated via high barriers, and therefore form distinct regions of configuration space, with interconversion between cages a rare event. However the role of the 6-ring in this interconversion is different between the two. This is an example of the importance of electronic structure in the chemistry of encapsulated metals. Whether the metal can form covalent bonds to the framework determines whether the 6-ring behaves as a thermodynamic trap or a high barrier.

A further effect of the different electronic structures of Pt and $\mathrm{Au}$ is the role of adsorbates. While the structure of M@zeolite complexes varies drastically with adsorbate type and loading for Pt, it is largely unaffected for Au, which bind adsorbates more weakly, and is agnostic towards the framework. 
The energetic differences between bare and adsorbate covered metal atoms manifest themselves kinetically, as shown by the results of microkinetic modelling. The simulations represent the idealized case of an infinitely low concentration of Pt atoms in the zeolite. They reveal that the naked $\mathrm{Pt}$ atom requires high temperatures to equilibrate on a timescale shorter than the laboratory scale. Therefore at low (room) temperature, it is reasonable to expect that non-equilibrium Pt distributions may be observed. Several studies have shown that in high-silica zeolites, single atoms and small clusters can be observed in high resolution TEM, despite the thermodynamic preference for sintering and expulsion from the pores. It remains an open question whether the trapped metals are all at Al sites, or whether some remain in siliceous cages or region of the framework. Our results suggest that in siliceous framework, such resistance to cluster growth is lost in the presence of reducing adsorbates, which occupy sites for short times, and equilibrate on much shorter timescales than observation can take place, even at low temperature (300 K).

\section{Conclusions}

Via a thorough, unbiased global structure prediction process, we have elucidated the potential energy landscapes for the binding and migration of noble metal atoms $\mathrm{Pt}$ and $\mathrm{Au}$ to the silicious zeolite LTA, in the presence (and absence) of common reducing adsorbates CO and $\mathrm{H}_{2}$. We find that for $\mathrm{Pt}$, which exhibits a strong chemical interaction with the siliceous framework, adsorbates weaken attachment, lower the barriers to migration and thereby dramatically reduce sintering resistance. This is related to the electronic shell closing that is achieved upon formation of covalent bonds between adsorbate and the metal atom. We predict that sintering mechanisms involving adsorbate-bound Pt atoms are likely to be significant contributors to growth of particles in reducing atmospheres. By contrast, $\mathrm{Au}, \mathrm{a}$ group 11 metal, exhibits a weak interaction with the framework, with negligible migration barriers. Kinetic modelling reveals that while the resistance to migration, and therefore growth is high for Pt in siliceous zeolites, and therefore long-term non-equilibrium behaviour 
is likely at low temperatures, the effect of adsorbates is to dramatically accelerate equilibration.

\section{Acknowledgments}

$\mathrm{CJH}$ acknowledges the support of the Czech Science Foundation (20-26767Y). The authors also acknowledge financial support from the Bavarian-Czech Academic Agency (BayerischTschechische Hochschulagentur) in the framework of the project "Entwicklung und Designprinzipien für strukturierte Materialien" financed by funds of the Free State of Bavaria. This work was supported by The Ministry of Education, Youth and Sports from the Large Infrastructures for Research, Experimental Development and Innovations project "eInfrastructure CZ - LM2018140.

\section{References}

1. Campelo, J. M.; Luna, D.; Luque, R.; Marinas, J. M.; Romero, A. A., Sustainable Preparation of Supported Metal Nanoparticles and Their Applications in Catalysis. ChemSusChem 2009, 2 (1), 18-45. 2. Ndolomingo, M. J.; Bingwa, N.; Meijboom, R., Review of supported metal nanoparticles: synthesis methodologies, advantages and application as catalysts. J. Mater. Sci. 2020, 55 (15), 6195-6241.

3. Dhakshinamoorthy, A.; Garcia, H., Catalysis by metal nanoparticles embedded on metal-organic frameworks. Chem. Soc. Rev. 2012, 41 (15), 5262-5284.

4. Astruc, D., Introduction: Nanoparticles in Catalysis. Chem. Rev. 2020, 120 (2), 461-463.

5. Li, Z.; Ji, S.; Liu, Y.; Cao, X.; Tian, S.; Chen, Y.; Niu, Z.; Li, Y., Well-Defined Materials for Heterogeneous Catalysis: From Nanoparticles to Isolated Single-Atom Sites. Chem. Rev. 2020, 120 (2), 623-682.

6. Koop, J.; Deutschmann, O., Detailed surface reaction mechanism for Pt-catalyzed abatement of automotive exhaust gases. Appl. Catal. B Environ. 2009, 91 (1), 47-58.

7. Iwamoto, M.; Yahiro, H., Zeolites in the Science and Technology of Nitrogen Monoxide Removal. In Handbook of Zeolite Science and Technology, Marcel Dekker: New York: 2003; pp 951-988.

8. Chen, Y.-Z.; Cai, G.; Wang, Y.; Xu, Q.; Yu, S.-H.; Jiang, H.-L., Palladium nanoparticles stabilized with $\mathrm{N}$-doped porous carbons derived from metal-organic frameworks for selective catalysis in biofuel upgrade: the role of catalyst wettability. Green Chem. 2016, 18 (5), 1212-1217.

9. Li, Y.; Li, L.; Yu, J., Applications of Zeolites in Sustainable Chemistry. Chem 2017, 3 (6), 928-949.

10. Zhang, Y.; Cui, X.; Shi, F.; Deng, Y., Nano-Gold Catalysis in Fine Chemical Synthesis. Chem. Rev. 2012, 112 (4), 2467-2505.

11. Dong, X.-Y.; Gao, Z.-W.; Yang, K.-F.; Zhang, W.-Q.; Xu, L.-W., Nanosilver as a new generation of silver catalysts in organic transformations for efficient synthesis of fine chemicals. Catal. Sci. Technol. 2015, 5 (5), 2554-2574.

12. Hülsey, M. J.; Zhang, J.; Yan, N., Harnessing the Wisdom in Colloidal Chemistry to Make Stable Single-Atom Catalysts. Adv. Mater. 2018, 30 (47), 1802304. 
13. Liu, L.; Corma, A., Metal Catalysts for Heterogeneous Catalysis: From Single Atoms to Nanoclusters and Nanoparticles. Chem. Rev. 2018, 118 (10), 4981-5079.

14. Kosinov, N.; Liu, C.; Hensen, E. J. M.; Pidko, E. A., Engineering of Transition Metal Catalysts Confined in Zeolites. Chem. Mater. 2018, 30 (10), 3177-3198.

15. Laursen, A. B.; Højholt, K. T.; Lundegaard, L. F.; Simonsen, S. B.; Helveg, S.; Schüth, F.; Paul, M.; Grunwaldt, J.-D.; Kegnæs, S.; Christensen, C. H.; Egeblad, K., Substrate Size-Selective Catalysis with Zeolite-Encapsulated Gold Nanoparticles. Angew. Chem. Int. Ed. 2010, 49 (20), 3504-3507.

16. Mielby, J.; Abildstrøm, J. O.; Wang, F.; Kasama, T.; Weidenthaler, C.; Kegnæs, S., Oxidation of Bioethanol using Zeolite-Encapsulated Gold Nanoparticles. Angew. Chem. 2014, 126 (46), 1272112724.

17. Xu, D.; Lv, H.; Liu, B., Encapsulation of Metal Nanoparticle Catalysts Within Mesoporous Zeolites and Their Enhanced Catalytic Performances: A Review. Front Chem. 2018, 6, 550.

18. Wang, N.; Sun, Q.; Yu, J., Ultrasmall Metal Nanoparticles Confined within Crystalline Nanoporous Materials: A Fascinating Class of Nanocatalysts. Adv. Mater. 2019, 31 (1), 1803966.

19. Vilhelmsen, L. B.; Walton, K. S.; Sholl, D. S., Structure and Mobility of Metal Clusters in MOFs: Au, Pd, and AuPd Clusters in MOF-74. J. Am. Chem. Soc. 2012, 134 (30), 12807-12816.

20. Ye, J.; Cramer, C. J.; Truhlar, D. G., Organic Linker Effect on the Growth and Diffusion of Cu Clusters in a Metal-Organic Framework. J. Phys. Chem. C 2018, 122 (47), 26987-26997.

21. Platero-Prats, A. E.; League, A. B.; Bernales, V.; Ye, J.; Gallington, L. C.; Vjunov, A.; Schweitzer, N. M.; Li, Z.; Zheng, J.; Mehdi, B. L.; Stevens, A. J.; Dohnalkova, A.; Balasubramanian, M.; Farha, O. K.; Hupp, J. T.; Browning, N. D.; Fulton, J. L.; Camaioni, D. M.; Lercher, J. A.; Truhlar, D. G.; Gagliardi, L.; Cramer, C. J.; Chapman, K. W., Bridging Zirconia Nodes within a Metal-Organic Framework via Catalytic Ni-Hydroxo Clusters to Form Heterobimetallic Nanowires. J. Am. Chem. Soc. 2017, 139 (30), 10410-10418.

22. Liu, Y.; Li, Z.; Yu, Q.; Chen, Y.; Chai, Z.; Zhao, G.; Liu, S.; Cheong, W.-C.; Pan, Y.; Zhang, Q.; Gu, L.; Zheng, L.; Wang, Y.; Lu, Y.; Wang, D.; Chen, C.; Peng, Q.; Liu, Y.; Liu, L.; Chen, J.; Li, Y., A General Strategy for Fabricating Isolated Single Metal Atomic Site Catalysts in Y Zeolite. J. Am. Chem. Soc. 2019, 141 (23), 9305-9311.

23. Wang, H.; Wang, L.; Xiao, F.-S., Metal@Zeolite Hybrid Materials for Catalysis. ACS Cent. Sci. 2020, 6 (10), 1685-1697.

24. Chai, Y.; Liu, S.; Zhao, Z.-J.; Gong, J.; Dai, W.; Wu, G.; Guan, N.; Li, L., Selectivity Modulation of Encapsulated Palladium Nanoparticles by Zeolite Microenvironment for Biomass Catalytic Upgrading. ACS Catal. 2018, 8 (9), 8578-8589.

25. Qin, R.; Liu, P.; Fu, G.; Zheng, N., Strategies for Stabilizing Atomically Dispersed Metal Catalysts. Small Methods 2018, 2 (1), 1700286.

26. Liu, L.; Díaz, U.; Arenal, R.; Agostini, G.; Concepción, P.; Corma, A., Generation of subnanometric platinum with high stability during transformation of a 2D zeolite into 3D. Nat. Mater. 2016, 16, 132. 27. Liu, L.; Corma, A., Confining isolated atoms and clusters in crystalline porous materials for catalysis. Nat. Rev. Mater. 2021, 6 (3), 244-263.

28. Zhang, Y.; Kubů, M.; Mazur, M.; Čejka, J., Encapsulation of Pt nanoparticles into IPC-2 and IPC-4 zeolites using the ADOR approach. Microporous Mesoporous Mater. 2019, 279, 364-370.

29. Zhang, Y.; Fulajtárová, K.; Kubů, M.; Mazur, M.; Shamzhy, M.; Hronec, M.; Čejka, J., Controlling dispersion and accessibility of Pd nanoparticles via 2D-to-3D zeolite transformation for shape-selective catalysis: Pd@MWW case. Materials Today Nano 2019, 8, 100056.

30. Gu, J.; Zhang, Z.; Hu, P.; Ding, L.; Xue, N.; Peng, L.; Guo, X.; Lin, M.; Ding, W., Platinum Nanoparticles Encapsulated in MFI Zeolite Crystals by a Two-Step Dry Gel Conversion Method as a Highly Selective Hydrogenation Catalyst. ACS Catal. 2015, 5 (11), 6893-6901. 
31. Liu, L.; Lopez-Haro, M.; Lopes, C. W.; Li, C.; Concepcion, P.; Simonelli, L.; Calvino, J. J.; Corma, A., Regioselective generation and reactivity control of subnanometric platinum clusters in zeolites for high-temperature catalysis. Nat. Mater. 2019.

32. Ryu, T.; Ahn, N. H.; Seo, S.; Cho, J.; Kim, H.; Jo, D.; Park, G. T.; Kim, P. S.; Kim, C. H.; Bruce, E. L.; Wright, P. A.; Nam, I.-S.; Hong, S. B., Fully Copper-Exchanged High-Silica LTA Zeolites as Unrivaled Hydrothermally Stable NH3-SCR Catalysts. Angew. Chem. Int. Ed. 2017, 56 (12), 3256-3260.

33. Hou, D.; Grajciar, L.; Nachtigall, P.; Heard, C. J., Origin of the Unusual Stability of ZeoliteEncapsulated Sub-Nanometer Platinum. ACS Catal. 2020, 10 (19), 11057-11068.

34. Liu, L.; Zakharov, D. N.; Arenal, R.; Concepcion, P.; Stach, E. A.; Corma, A., Evolution and stabilization of subnanometric metal species in confined space by in situ TEM. Nat. Commun. 2018, 9 (1), 574.

35. Broach, R. W., Zeolite Types and Structures. In Zeolites in Industrial Separation and Catalysis, Kulprathipanja, S., Ed. WILEY-VCH Verlag GmbH \& Co: KGaA, Weinheim, 2010.

36. Wales, D. J.; Doye, J. P. K., Global Optimization by Basin-Hopping and the Lowest Energy Structures of Lennard-Jones Clusters Containing up to 110 Atoms. J. Phys. Chem. A 1997, 101 (28), 5111-5116.

37. Wales, D. J.; Scheraga, H. A., Global Optimization of Clusters, Crystals, and Biomolecules. Science 1999, 285 (5432), 1368.

38. Perdew, J. P.; Burke, K.; Ernzerhof, M., Generalized Gradient Approximation Made Simple. Phys. Rev. Lett. 1996, 77 (18), 3865-3868.

39. Grimme, S.; Antony, J.; Ehrlich, S.; Krieg, H., A consistent and accurate ab initio parametrization of density functional dispersion correction (DFT-D) for the 94 elements H-Pu. J. Chem. Phys. 2010, 132 (15), 154104.

40. Hjorth Larsen, A.; Jørgen Mortensen, J.; Blomqvist, J.; Castelli, I. E.; Christensen, R.; Dułak, M.; Friis, J.; Groves, M. N.; Hammer, B.; Hargus, C.; Hermes, E. D.; Jennings, P. C.; Bjerre Jensen, P.; Kermode, J.; Kitchin, J. R.; Leonhard Kolsbjerg, E.; Kubal, J.; Kaasbjerg, K.; Lysgaard, S.; Bergmann Maronsson, J.; Maxson, T.; Olsen, T.; Pastewka, L.; Peterson, A.; Rostgaard, C.; Schiøtz, J.; Schütt, O.; Strange, M.; Thygesen, K. S.; Vegge, T.; Vilhelmsen, L.; Walter, M.; Zeng, Z.; Jacobsen, K. W., The atomic simulation environment-a Python library for working with atoms. J. Phys.: Condens. Matter 2017, 29 (27), 273002.

41. Tian Lu, Molclus program. http://www.keinsci.com/research/molclus.html accessed on Oct 15, 2020.

42. Bannwarth, C.; Caldeweyher, E.; Ehlert, S.; Hansen, A.; Pracht, P.; Seibert, J.; Spicher, S.; Grimme, S., Extended tight-binding quantum chemistry methods. WIREs Computational Molecular Science 2021, 11 (2), e1493.

43. Tang, W.; Sanville, E.; Henkelman, G., A grid-based Bader analysis algorithm without lattice bias. J. Phys.: Condens. Matter 2009, 21 (8), 084204.

44. Sanville, E.; Kenny, S. D.; Smith, R.; Henkelman, G., Improved grid-based algorithm for Bader charge allocation. J. Comput. Chem. 2007, 28 (5), 899-908.

45. Henkelman, G.; Arnaldsson, A.; Jónsson, H., A fast and robust algorithm for Bader decomposition of charge density. Comput. Mater. Sci. 2006, 36 (3), 354-360.

46. Yu, M.; Trinkle, D. R., Accurate and efficient algorithm for Bader charge integration. J. Chem. Phys. 2011, 134 (6), 064111.

47. Henkelman, G.; Uberuaga, B. P.; Jónsson, H., A climbing image nudged elastic band method for finding saddle points and minimum energy paths. J. Chem. Phys. 2000, 113 (22), 9901-9904.

48. Henkelman, G.; Jónsson, H., A dimer method for finding saddle points on high dimensional potential surfaces using only first derivatives. J. Chem. Phys. 1999, 111 (15), 7010-7022. 
49. Henkelman, G.; Jónsson, H., Improved tangent estimate in the nudged elastic band method for finding minimum energy paths and saddle points. J. Chem. Phys. 2000, 113 (22), 9978-9985.

50. Akdogan, Y.; Anantharaman, S.; Liu, X.; Lahiri, G. K.; Bertagnolli, H.; Roduner, E., Reconstruction of Pt13 Clusters into Pt2(CO)m on CO Addition in NaY Zeolite. J. Phys. Chem. C 2009, 113 (6), 2352-2359. 51. Chaâbane, N.; Lazzari, R.; Jupille, J.; Renaud, G.; Avellar Soares, E., CO-Induced Scavenging of Supported Pt Nanoclusters: A GISAXS Study. J. Phys. Chem. C 2012, 116 (44), 23362-23370.

52. Keppeler, M.; Bräuning, G.; Radhakrishnan, S. G.; Liu, X.; Jensen, C.; Roduner, E., Reactivity of diatomics and of ethylene on zeolite-supported 13-atom platinum nanoclusters. Catal. Sci. Technol. 2016, 6 (18), 6814-6823.

53. Mojet, B. L.; Koningsberger, D. C., CO-induced decomposition of small Pt particles in K-LTL zeolite. Catal. Lett. 1996, 39 (3), 191-196.

54. Bliem, R.; van der Hoeven, J. E. S.; Hulva, J.; Pavelec, J.; Gamba, O.; de Jongh, P. E.; Schmid, M.; Blaha, P.; Diebold, U.; Parkinson, G. S., Dual role of CO in the stability of subnano Pt clusters at the Fe304(001) surface. Proc. Natl. Acad. Sci. U.S.A. 2016, 113 (32), 8921.

55. Kuendig, E. P.; McIntosh, D.; Moskovits, M.; Ozin, G. A., Binary carbonyls of platinum, Pt(CO)n (where $n=1-4)$. Comparative study of the chemical and physical properties of $M(C O) n$ (where $M=$ nickel, palladium, or platinum; $n=1-4)$. J. Am. Chem. Soc. 1973, 95 (22), 7234-7241.

56. Doerr, M.; Frenking, G., Why are the Homoleptic Diyl Complexes $M(\operatorname{InR}) 4$ with $\mathrm{M}=\mathrm{Ni}$ and Pt Stable Compounds while only $\mathrm{Ni}(\mathrm{CO}) 4$ but not $\mathrm{Pt}(\mathrm{CO}) 4$ can become Isolated? A Theoretical Study of $\mathrm{M}(\mathrm{EMe}) 44$ and $\mathrm{M}(\mathrm{CO}) 4$ ( $\mathrm{M}=\mathrm{Ni}, \mathrm{Pd}, \mathrm{Pt} ; \mathrm{E}=\mathrm{B}, \mathrm{Al}, \mathrm{Ga}, \mathrm{In}, \mathrm{Tl})$. Z. Anorg. Allg. Chem. 2002, 628 (4), 843850.

57. Liang, B.; Andrews, L., Reactions of Laser-Ablated Ag and Au Atoms with Carbon Monoxide: Matrix Infrared Spectra and Density Functional Calculations on $\operatorname{Ag}(\mathrm{CO}) \mathrm{n}(\mathrm{n}=2,3), \mathrm{Au}(\mathrm{CO}) \mathrm{n}(\mathrm{n}=1,2)$ and $M(C O) n+(n=1-4 ; M=A g, A u)$. J. Phys. Chem. A 2000, 104 (40), 9156-9164.

58. Phala, N. S.; Klatt, G.; Steen, E. v., A DFT study of hydrogen and carbon monoxide chemisorption onto small gold clusters. Chem. Phys. Lett. 2004, 395 (1), 33-37. 